\title{
Something old is something new: The role of heritage preservation in economic development
}

\author{
Rebecca Goddard-Bowman, Ec.D.
}

\begin{abstract}
Heritage preservation has been gaining considerable momentum as a way to contribute to local economic development. This paper examines how it has led to economic growth in Canada and has strengthened communities in small towns and big cities. The author argues that preserving heritage buildings and artifacts can play a key role in promoting local economic development as it has the ability to create jobs, increase property value, generate added tax revenues, act as a catalyst for new industry development, provide space for new business attraction and create added value for a community through an improved quality of life.
\end{abstract}

Keywords: heritage preservation, local economic development, community development

Traditionally, the mandate of local economic development has encompassed a wide variety of initiatives with a clear focus on job creation and sustainability. This mandate has involved promoting the development of a number of sectors including both industrial and commercial. The emphasis has been on the creation of the 'modern' and 'new' with less attention devoted to the 'old'.

An area of development that has emerged and is gaining considerable momentum is heritage preservation. This paper will examine the role that this initiative is having on local economic development and growth, as well as its effect on strengthening communities ranging from small towns to big cities.

Heritage preservation, consisting of the conservation of historical buildings and artifacts, has existed for decades, even longer, but not always in parallel with economic development. Conventionally, the conservation of heritage property has been viewed as 'a frill, or worse, a net cost without economic benefit' (Heritage Canada Foundation, 2001). It has often been viewed as an elitist area of interest valued extensively by activist-type individuals or groups devoted to preserving the old. But just as heritage preservation has been valued for its aesthetic, social, cultural and historical merit, its economic value must also be upheld (HCF, 2001).

Heritage conservation approached from an economic context is complex. Its affects are wide reaching, encompassing not just built heritage, but also job creation, tax assessment, the issue of urban sprawl, and quality of life. In other words, its effects can be measured both qualitatively and quantitatively. Dr. Rob Pickard of the University of Northumbria, Newcastle, England states: 
"Heritage should be thought of in terms of cultural value (defining sense of place, distinctiveness), educational and academic value (evolution of society and knowledge for planning the future), economic value (economic development, employment, tourism, social and functional diversity, including mixed uses in rehabilitated buildings), resource value (reusing resources and saving costs associated with demolition and redevelopment), recreational value (life enjoyment), and an aesthetic value (quality of environment)" (HCF, 2001).

Often perceived as being just aesthetically pleasing, beautiful and much admired, historical places truly serve as dynamic, multifunctional entities encompassing residential, commercial, social and economic activity. Sustainable cultural heritage includes not only preservation of properties and community areas of cultural significance, but also fosters the promotion of a variety of factors and activities to meet a community's development and growth objectives. Heritage preservation is, in itself, an example of effectively promoting ongoing community sustainability.

Individuals with a long time interest in the purest form of heritage conservation caution that preservation must not be simply viewed as a basis for economic value. The importance of saving and maintaining our Canadian heritage, as well as the quality of life and community confidence it echoes, must be given equal weight along with property values, income, return on investment and other monetary measures. Dr. Robert Shipley, Associate Professor, School of Urban and Regional Planning, University of Waterloo, Ontario notes:

"It is heritage that gives economic value, not economics that gives value to heritage" (HCF, 2001).

Essentially, economic development can be approached within the context of historic preservation.

\section{Creating sustainable communities through preservation}

Built heritage has become a contributing factor in economic development and growth and, in the process, the revitalization of communities. Heritage preservation has, in many ways, reached beyond advocacy initiatives and is now being embraced in new public policy and economic development initiatives. By making development decisions to reuse historic buildings, the integrity and vitality of a community is preserved, creating a magnet for new investment. 


\section{Revitalization of communities}

In the last half-century, many economic and socio-economic factors have had a negative effect on communities leaving in their wake threatened sustainability. These factors include increased human mobility, de-centralized shopping patterns, de-industrialization and the depletion of resources, to name a few. These effects have been felt in Canada, United States, United Kingdom and Europe. The results are similar. The customer base for shops diminishes, offices close, proprietors cannot afford to maintain buildings, businesses either fail or cannot afford to maintain their premises, property values fall, vandalism and crime increase, and the community begins to lose confidence and vitality (HCF, 2001). To reverse the downward spiral, many communities have turned to heritage preservation to be an engine of economic rebirth. These communities view their historically significant buildings and artifacts as community assets and in turn, new businesses and new industries have developed.

Over the past five years, through the Historic Rehabilitation Tax Credit program, private investors in the United States have spent more than $\$ 2.9$ billion (US) to preserve and restore nearly 1,300 historic properties - everything from hotels to residential neighbourhoods to former warehouses and industrial districts. "In many cities," says Fred Copeman, a partner at Ernest and Young LLP in Boston, "historic restoration projects have become the spark plug for revitalization of entire neighourhoods" (Jenish. 2002).

\section{Commercial heritage development}

Although the role of residential restoration has been one of the strongest components of the heritage preservation movement, the revitalization of commercial properties has also been predominant, mostly in larger urban centres. Just as new buildings are built to house office and retail space, historic commercial properties are being restored to encourage new investment.

The City of Saint John captured the prestigious Heritage Canada Foundation Prince of Wales award in 2002 for heritage recognition and preservation. Their efforts facilitated through partnerships formed between the municipality and building owners, have led to the preservation of the city's rich historic commercial buildings. High-tech companies have discovered the marketing benefits associated with a historic building as an address - a perception of stability and respectability. Giving renewed life to older building stock is a trend that cutting-edge companies are embracing (Roy, 2003)

Mixing the modern with the old, the inner city neighbourhood of historic West Toronto Junction is another example of successful commercial heritage development. To enhance the area's thriving economic development, digital and media economy businesses, bandwidth providers and local building owners have begun transforming the historic commercial Dundas Street between 
Runneymede and Keele Streets into a centre for new media business. The project will include the revitalization of 325 commercial and industrial buildings and offer nearly 1,000,000 square feet of both commercial and industrial workspace to accommodate up to 3,500 media professionals. The new broadband facilities and services will serve the needs of the new media and digital economy. This will benefit the West Toronto Junction neighbourhood as well as surrounding communities. Even with the existence of old, heritage structures, the Junction has the necessary building blocks to become a 'Digital-media Cluster' or a 'New Media Node' in the City of Toronto. Over a one year period, between September, 2000 and August, 2001, over 45 new businesses became established in the area, a minimum of 80 jobs were generated and $\$ 1.5$ million was invested in interior and exterior improvements.

\section{Downtown revitalization}

The baby boom, directly following World War II and continuing into the early 1960s, contributed to the tremendous growth of suburban areas. The urban sprawl began and with it new commercial development sprang up in these areas to serve the needs of the new population. Major shopping centres and strip malls began to draw customers away from the traditional shopping domain of the downtown core. This trend continues today, with the infusion of big box stores, leaving the core of urban areas in a state of decay. This issue is on the minds of many economic development professionals who are challenged to find new ways of bringing the people back to what was the heart of the community.

Almost all downtowns have a core area with old buildings, often decaying and unoccupied. Many downtowns are vast in size, often occupying several blocks with active retail and service business dotting the streetscape. It is evident that tearing down these structures is an impossible thought. It would threaten what is still very much a central and, at times, the key commercial area for communities. Most of all, it would destroy valuable historic assets and the quality of life these bring.

To renew economic growth, municipalities and specifically economic development departments, are developing strategic plans to draw new business and community activity back to the downtowns. One of the obvious strategies is the preservation of the historic structures. The restoration of commercial buildings, theatres, town halls and community meeting places all represent the basis for revitalization.

In the Municipality of Port Hope, Ontario, the heritage district of Walton Street is an example of preservation and revitalization success. Faced with the same fate as many downtowns, Port Hope's preservation minded community members began purchasing buildings and restoring them. Sparked by the tragic flood of 1980 that nearly destroyed the downtown core, private investment was the turning point toward revitalization. Its efforts were rewarded with 'The Best 
Preserved Main Street' award from TVOntario (TVO). Port Hope's downtown has become a magnet for antique stores and unique specialty shops. The tourism industry continues to be one of Port Hope's fastest growing industries with the main street being the key destination. Vacant storefronts are virtually extinct and the core of the municipality has become a sustainable district within itself. The continued restoration of a downtown storefront building into a Performing Arts Centre is the latest example of continued investment in the history of Port Hope. The \$2.3 million renovation is an extension of The Capitol Theatre, Canada's oldest operating atmospheric theatre. It is expected to produce spin offs of $\$ 3$ million and many new jobs for the local economy. Restaurants, shops and accommodations will be affected positively by an increase in visitors and new businesses will emerge to meet the needs of the growing tourism industry.

However, heritage conservation alone does not revitalize downtowns. Revitalization is the result of many forms of investment but heritage preservation can initiate new investment opportunities.

\section{Urban Sprawl management (smart growth)}

Smart Growth was introduced by the Province of Ontario's Ministry of Municipal Affairs and Housing to ensure that decisions on public investment help to improve economic competitiveness, protect and enhance the environment and build liveable communities. Many economic development initiatives are utilizing the Smart Growth concepts as the basis for landuse planning and community development. Smart Growth emphasizes the importance of planning for the reduction of 'mindless' urban sprawl and the creation of compact, efficient communities. Dr. Gotlieb, Chair of the Ontario Heritage Foundation commented on this at the 2001 Heritage Canada Foundation Conference:

\footnotetext{
"There are certain elements of Smart Growth that make it a welcome ally for heritage. An important part is to stress conservation values as an approach to development that is sensitive to people and place. In jurisdictions that are implementing Smart Growth strategies, there is a strong commitment to the protection of natural areas and to cultural heritage."
}

Embracing the Smart Growth program should involve making the best use of heritage infrastructure. Many communities across North America have used heritage preservation to reverse serious decline and initiate the revitalization of the downtown core and the renaissance of neighbourhoods. Ultimately this involves more than just the saving of historic assets to include new projects. Rejuvenating already developed areas conserves remaining open space, eliminates outward expansion and the need to create new and expensive infrastructures. Restoring old buildings creates jobs and space for new businesses. 


\section{Brownfield redevelopment}

Brownfield redevelopment is a part of the Smart Growth Strategy. Brownfields, which are defined as lands and buildings that were once used for industrial or commercial activity but which are no longer in use, can be found in virtually every community in Ontario. From cities to small rural areas, brownfields are often underused, derelict or abandoned and have often become the 'eye sores' of communities. Because of their history, many are contaminated which is often a disincentive for redevelopment. However, because of their history, brownfields are often a valuable part of a community's heritage. As a result, many of these sites are designated as heritage sites despite their neglected condition.

Brownfields, and more specifically heritage brownfields, are being recognized as potential catalysts for attracting new revenue, investment and people. They are being embraced for their economic development value with the ability to create jobs, increase tax revenues, revitalize derelict, contaminated areas and develop new cultural, commercial and educational opportunities.

The newly restored Gooderham and Worts industrial village in Toronto, now marketed as 'The Distillery', is being hailed as one of the finest and most complex brownfield restoration projects in Canada. Dating back to 1832 and built over a period of 80 years, The Distillery's 44 building complex sprawls over a five hectare area close to the heart of the city. It is the largest and best preserved collection of Victorian industrial architecture in North America. Toronto's Cityscape purchased the property in 2001 with an ambitious plan to restore and revitalize The Distillery District. Opened in the Spring of 2003, with an occupancy rate of 80 percent, The Distillery District is now occupied by a mix of tenants that combine culture with commercial and retail. Restaurants, shops, bars, coffee houses, art galleries, studios and breweries make up the 119 unique occupants. Plans are underway for $\$ 14$ million joint venture between Soulpepper Theatre and George Brown College that will combine theatre training and performance at one site. The Distillery will also be home to events such as The Distillery Jazz Festival.

The Distillery is expected to generate millions of dollars and provide jobs and entrepreneurship opportunities for hundreds of people. The role it once played in the development of Toronto will once again be repeated in a new legacy encompassing brownfield redevelopment, cultural and commercial development and economic growth.

\section{Economic impact: Added value}

The mandate of economic development involves the creation of initiatives that will have a positive effect on the economy. Heritage preservation is an initiative that can be the basis for economic development, growth and renewal. It has the ability to create jobs, increase property 
value, generate added tax revenues, act as a catalyst for new industry development, provide space for new business attraction and create added value for a community through an improved quality of life.

Dr. David Listokin and Dr. Michael Lahr, professors at the Center for Urban Policy Research at Rutgers University, New Brunswick, New Jersey have conducted pioneering research in the economics of heritage property conservation, historic sites, heritage tourism and the voluntary sector. Their New Jersey economic impact of historic preservation study concluded that annually there was approximately $\$ 123$ million (US) in historic rehabilitation, 9.1 million adult heritage travellers who spent $\$ 423$ million, plus an additional $\$ 25$ million in spending by historic sites and organizations. It was estimated that the $\$ 123$ million in historic rehabilitation resulted in 4,600 jobs, $\$ 156$ million in income and $\$ 41$ million in tax revenues.

It can be argued that any economic activity would generate these numbers and that rebuilding is often cheaper and more profitable than refurbishing. But with 21 to 23 per cent of Canada's historically or architecturally significant buildings demolished to make way for newer ones, the historic resources that create communities with a strong sense of identity and place will disappear. This is how historic preservation takes on a meaning that goes beyond the dollars and cents of its economic potential and becomes a priceless and valuable asset.

\section{Cultural and heritage tourism}

The tourism industry is one of the leading industries in Canada. One of the most significant roles for heritage preservation is in the tourism industry. While alone the preservation of historic buildings may not necessarily be an attraction, they do represent an important part of an area's unique heritage. It is part of an overall package of urban and rural landscapes, architecture, streetscapes, natural areas and historic places. Historic and heritage resources accounted for nearly two thirds of Ontario's cultural tourism resources of which 41 per cent were built heritage resources. These built heritage resources were almost exclusively linked to historic sites (84 per cent) and cultural interpretive centres (13 per cent).

Cultural and heritage tourism can be defined as "travel concerned with experiencing cultural environments, including landscapes, the visual and performing arts, and special lifestyles, values, traditions and events" (Nordic World Heritage Office, 1999). Cultural and heritage tourism occurs when participation in a cultural or heritage activity is a significant factor for travelling (HCF, 2002).

Many tourists are drawn to Canada by the performing arts, festivals, museums, art galleries, archaeological sites, and other built heritage. Domestic tourists are also drawn to the displays of Canadian history whether in their own communities or beyond. Both types of tourists represent a 
significant source of revenues for the cultural sector and provide a strong economic stimulant. Cultural spending by tourists in Canada reached more than $\$ 1$ billion, representing about 3 per cent of tourists' total expenditures. Cultural spending increased 7.6 per cent annually between 1996 and 1999. Cultural spending by Canadian tourists, accounting for almost $\$ 400$ million or 37 per cent of culture spending by all tourists (domestic and foreign) in 1999, increased about 8 per cent annually between 1996 and 1999. Canadians are now the second largest tourism market after the U.S. American tourists accounted for $\$ 411$ million or 39 per cent of the total, with overseas visitors accounting for the other $\$ 247$ million (or 23 per cent) in 1999. Increasing numbers of American travellers have been coming to Canada to see cultural events and attractions with the number of cultural activities visited reaching more than 61 million in 1999, a 17 per cent increase over 1996.

Colorado is one of 26 states in the U.S. that have developed heritage tourism programs. Visitors are attracted to Colorado's thriving historic sites from large cities to rural areas. They provide a significant source of revenue for local and state economies. Produced in 1999, Longwoods International's Colorado Visitor Study revealed the following heritage tourism information:

In 1999:

- 4.6 million trips to Colorado (22 percent of 20.8 million) represented overnight pleasure trips;

- $\$ 1.4$ billion represented direct heritage tourist expenditures;

- $\$ 1.7$ billion represented indirect heritage tourist expenditures;

- $\$ 3.1$ billion total expenditures;

- $\$ 1.0$ billion in total household earnings generated;

- 55,300 jobs generated (Advisory Council on Historic Preservation, 2003).

The study also documented a detailed analysis of trends involving Colorado's heritage tourists:

- heritage tourists spend slightly more per day (\$58 per visitor) than other tourists (\$55 per visitor);

- heritage tourists stay in Colorado a little longer than other vacationers - an average of 5.3 nights in the state, versus an average of 5.1 nights for other vacationers;

- tourists who include visits to historic sites or landmarks on their trip to Colorado are more likely to stay in a hotel or motel (versus the homes of friends and relatives) than other vacationers;

- heritage tourists tend to be older than other visitors. More than half of heritage tourists in 1999 were 45 years old or older;

- visitors to historic sites and landmarks are more likely to be retired than other tourists;

- heritage tourists are more likely than other visitors to visit a national or state park, or to watch birds and other wildlife, and to visit a museum; 
- heritage tourists are more likely to try unique local foods, and to hike, swim, fish, backpack, bike and river raft on their trip than other travellers;

- approximately 30 per cent of heritage travelers have household incomes of over $\$ 75,000$ per year (Colorado Historical Society, 2002).

It is generally accepted that culture and heritage contribute to tourism with the preservation of heritage buildings, or built heritage providing the basis for many attractions. Heritage tourism includes attributes such as land scapes, buildings, traditions and the like that are literally or metaphorically passed on from generation to generation and can be marketed as 'product'. The Canadian Tourism Commission focuses on five cultural and heritage tourism product lines:

- performing arts;

- visual arts and crafts;

- museums and cultural centres;

- historic sites, villages and interpretive centres;

- festivals.

As tourism is an integral part of economic development, these product lines become new initiatives for economic growth.

Saint John, Newfoundland continues to expand its inventory of historic buildings including cataloguing potential heritage resources. The number one reason cited by tourists for choosing to visit Saint John is the attraction of its heritage architecture. Saint John is well positioned to capitalize on the growing cultural and heritage tourism sector. Cruise ships have recently discovered the city, adding an average of 90,000 visitors each year. For the City of Saint John, the benefits of sound heritage preservation practices are increasingly evident in the growing cultural tourism industry.

The potential of tourism-driven revitalization depends on resources that can be developed into products, the financial capacity of public and private partners to do so, and political will. Montreal is one of the pre-eminent cities for recognizing and developing its built heritage as part of an overall strategy to improve the quality of life for its residents and diversify the economy. Tourism has emerged as a key component of its economic development efforts particularly since the early 1980s, after Montreal lost a large proportion of manufacturing jobs.

\section{Community policy development for heritage preservation}

Policy development for community preservation begins at the local level in conjunction with provincial and federal programs, strategies and incentives. Although provincial and federal programs assist by creating a framework from which initiatives emerge, communities and cities 
that have an interest in cultivating heritage preservation must develop their own 'hands-on' policy and corresponding strategies.

Currently, local efforts are often fragmented and involve an ad hoc approach. Success is often cultivated by individual or group efforts with private sector involvement taking on a leadership role. The strength of Architectural Conservancy of Ontario (ACO) and Local Architectural Conservancy Advisory Committee (LACAC) chapters are often directly involved and responsible for advancing local heritage preservation.

Municipal government plays a key role in leading community policy development. A truly holistic approach to heritage preservation must include a municipally driven umbrella policy that:

- states the community's dedication to a well-defined preservation initiative;

- declares and defines the leadership role of municipal government;

- incorporates the policies, strategies and programs of provincial and federal governments;

- marries existing local policies eg. heritage signage guidelines, existing incentive programs, etc.;

- outlines the potential development of incentive programs;

- outlines the potential for building partnerships with heritage based organizations (eg. LACAC, ACO), private investors and community interest groups;

- incorporates tourism strategies;

- defines the potential for brownfield redevelopment;

- incorporates land-use planning strategies;

- integrates existing or is incorporated into new official plan policies;

- incorporates economic development strategies;

- incorporates cultural development strategies;

- defines the vision of the community and includes public input.

Many municipalities and cities have already established policies for heritage preservation which demonstrate the political will necessary to ensure successful preservation initiatives that will ultimately benefit a community economically, culturally and socially.

\section{Heritage preservation incentives}

In the context of policy development, the importance of heritage incentives for property redevelopment cannot be understated. Mr. Allan Gotlieb, Chair of the Ontario Heritage Foundation states:

"Incentives are perhaps the single most important instrument of public policy that can unleash the creativity in the private sector. Tax incentives for heritage preservation 
are one of the ways in which this energy, creativity and ambition can be harnessed and unleashed. The sympathetic tax environment is both economic and psychological in triggering this" (HCF, 2001).

Incentives ensure that developers and owners receive some recognition in society for contributing to the preservation of our past and, in the process, provides them financial support. Incentives are essential for advancing economic development heritage preservation. Designated properties and restrictions imposed on historic properties often entail additional costs for restoration and maintenance. To entice people to protect historic properties, it is felt that governments should share the burden of preserving and maintaining historic sites.

New York, Miami, Denver and Victoria, British Columbia are examples of cities that successfully use tax incentives to encourage core development and which have obtained results in revitalizing and transforming their downtowns (HCF, 2001). One of the keys to Victoria's successful preservation program is its approach of 'leading by incentives'. The city has created a number of successful financial assistance programs which encourage owners to obtain heritage designation in order to apply for funding (Barber, 2002). One such assistance program is the Victoria Civic Heritage Trust (VCHT) established in 1989. The mandate of this program is to 'develop, administer and financially support programs that preserve, promote, interpret and enhance the cultural and natural heritage resources of the city and its environs' (Barber, 2002). Under the Building Incentive Program, monetary grants are awarded on a 50/50 matching basis for the conservation of commercial and institutional heritage buildings. Originally limited to downtown, the program expanded in 1996 to include all heritage based buildings throughout the city. As of Spring, 2002, the trust had awarded over $\$ 1,180,000$ in funding, while encouraging approximately $\$ 11.9$ million in private investment with a ratio of 1:10 of public investment to private investment. As a result, a more attractive and economically vibrant downtown has emerged along with the development of new commercial facilities and sectors.

In order for municipalities to instill such incentive programs, they must rely on the legislative framework and funding programs of the provincial and federal governments. In December, 2001, the Ontario government introduced a new incentive program under the Ontario Responsible Choice for Growth and Fiscal Responsibility Act - Bill 127. Municipalities may now offer a property tax reduction or refund to owners of designated properties, by creating a by-law that allows a tax credit of between 10 and 40 per cent of the total tax bill and any additional criteria that the municipality may wish to include as guidelines pertaining to the incentive. To qualify, the owner must agree to have property designated under the Ontario Heritage Act, enter into a heritage easement agreement with either the municipality or the Ontario Heritage Foundation, and abide by all local provisions. The easement is a covenant 
between the owner and the easement holder stating that the easement holder must approve any changes affecting the heritage character of the property.

In 2002, the Municipality of Port Hope, Ontario was one of the first to utilize the legislation with the introduction of their new heritage brownfield tax incentive by-law. When they took into account the fact that Bill 56, under the Ontario brownfield legislation, had not included incentives for brownfields, they integrated brownfield development with Bill 127 legislation. Building owners who qualify can apply for a grant of up to 40 per cent of their increase in taxes (municipal portion) resulting from an increase in the value of the property that is directly attributed to a remediation and restoration project. The grant for this portion of the taxes is capped at $\$ 10,000$ per annum for a maximum period of ten years. Forty per cent of the educational tax portion is also eligible subject to approval by the Minister of Finance. The Municipality of Port Hope hopes to restore heritage industrial properties that have become dilapidated.

\section{What does the future hold?}

What does the future hold for the role of heritage preservation in economic development? Canada lags behind many countries, in particular the United States and European nations, in establishing public policy, strategies and incentives to further promote heritage preservation. In the United States, incentives in the form of tax credits have been a powerful tool in preserving thousands of buildings. But in Canada, programs have been sporadic. Over the years, federal, provincial and municipal governments have offered financial incentives to encourage preservation. Most have been short-lived - introduced in a budget with funding for a prescribed period of time - and the approaches have varied from place to place. A consistent, welldeveloped and well-integrated program is required to tap into the huge potential that can act as a catalyst for advancing economic development and growth through heritage preservation. Sheila Copps, Minister of Canadian Heritage agrees:

"We're the only country in the G8 that has no national heritage strategy. If you look at the renaissance that has occurred in U.S. cities, it is largely driven by heritage construction" (Jenish, 2002).

The Prime Minister in May 2001, announced a major increase in funding for arts and culture, which included \$24 million over three years to support what has become known as the Historic Places initiative. But Minister Sheila Copps continues by saying:

"It's so much cheaper to do redevelopment that preservation won't happen until there's a level playing field. Incentives must entice the private sector to get involved in heritage development in the same way the film tax credit has encouraged the film industry across 
the country. We have to get the private sector involved because governments can't afford to do it alone" (Jenish, 2002).

While the Canadian Heritage program is a step in the right direction, co-ordinated policy, programs and political will need to cohesively exist at all levels of government to ensure that Canada's rich heritage is preserved, the full economic potential is reached and economic development professionals have the necessary tools to work with.

\section{Conclusion}

It is evident that heritage preservation is capable of playing a key role in promoting local economic development. In accepting, "if you build it, they will come," previous generations have provided the infrastructure that can effectively be employed to promote local economic development and growth. Preserving heritage buildings and artifacts provides the opportunity for communities to attract and create new industries and to establish a quality of life to be enjoyed for generations to come.

\section{Author Biography}

Rebecca Goddard-Bowman has a total of fifteen years experience in marketing, retail and business consulting with eight of those years in the field of economic development. After moving from Toronto to Cobourg, Ontario, Rebecca formed her own consulting business specializing in retail operations and downtown revitalization. She continued her work in business development as a Business Consultant for the Northumberland Business Self-Help Office through the Ministry of Enterprise, Innovation and Opportunity, and then as the Economic Development Officer for the Municipality of Port Hope. Ms. Goddard-Bowman has a B.A.A. (Bachelor of Applied Arts) in Retail Management from Ryerson University. She received her Certified Economic Developer Designation (Ec.D.) in 2002.

\section{References}

Abdel-Aziz, Ahab and Shari Elliott. (2001). The Greening of Brownfields. Building, pp. 39-40.

Advisory Council on Historic Preservation. (2003, May 8). ACHP Chairman Nau Speaks on "The Economic Potential of Preserving America", Economic Development Administration's National Conference Session on Entrepreneurship in Economic Development, Washington, D.C.

Barber, Steve. (2002). Victoria Captures Prestigious Prize. Heritage. Spring edition, pp. 23-26. 
Colorado Historical Society. (2002). Office of Archaeology and Historic Preservation, Economic Benefits of Historic Preservation in Colorado, January, pp. 16-19.

Copps, Sheila. (2003). Canada's Historic Places Initiative. Heritage. Spring edition, pp. 26.

Dolan, Alison. (2002). Rehabilitations Illustrate Power Of Preservation. Preservation in Progress. Virginia Department of Historic Resources Newsletter, September.

Heritage Canada Foundation. (2001). Preservation Pays: The Economics of Heritage Conservation, Proceedings, Heritage Canada Foundation Conference, October 11-13, 2001 Toronto.

Heritage Canada Foundation. (2002). Built Heritage: Assessing a Tourism Resource; Research Report.

Heritage Institutions. (2001). 1999-2000 Culture Statistics, Statistics Canada, Culture, Tourism and the Centre for Education Statistics.

Jenish, D'Arcy. (2002). What is old is new again: Heritage projects are breathing new life into old towns and cities. Forum, Vol.26 (6), pp. 16-21.

Nordic World Heritage Office. (1999), Sustainable Tourism and Cultural Heritage: A review of Development Assistance and Its Potential to Promote Sustainability, Oslo: NWHO, pp.2.

Roy, Ron J. (2003). Saint John Captures Prince of Wales Prize. Heritage. Winter edition, pp. 2729.

Stronberg, Richard L. (2002). New Act Offers Lower Taxes For Heritage Property Owners in Ontario. Heritage. Spring edition, pp. 29.

Varin, Francois. (2002). Heritage As An Engine For Economic Development. Heritage. Winter edition, pp. 29-31.

Virginia Department of Historic Resources Newsletter. (2002). 1999 Year End Report: Virginia's Sustainable Future: Solutions Through Historic Preservation. Preservation in Progress, January edition.

Whiting, P.G. \& Associates. (1985). Economic Impacts of Heritage Institutions on the Canadian Economy: Discussion Paper: Analysis of Method, Canadian Museums Association, March edition. 